Open Access

\title{
Dispute formatting: dispute transformation in case filing
}

Tao Zhu

Correspondence: jutor123@163.com National Institute of Social Development, Chinese Academy of Social Sciences, Beijing, China

\begin{abstract}
Many existing studies focus on disputes and resolutions but often overlook the transformation of disputes. Based on an analysis of case filing, this article explains how various factors of daily life enter the legal world through dispute formatting. When disputes are developed into lawsuits, the systematic logic of law and the logic of daily life constantly interact with each other. Dispute formatting appears at two stages: "internal filtering" and "external packaging", which includes defining, naming, formalizing, and documenting disputes. The "filtering-packaging" mechanism is the key in dispute transformation. This mechanism demonstrates judicial procedures and conventions that mutually restrain and limit each other in their interactions, and to a certain extent facilitates the interchange and fusion between the legal world and real life.
\end{abstract}

Keywords: Dispute transformation, Dispute formatting, "Filtering-packaging" mechanism

\section{Advance of questions}

Disputes have traditionally been an important research area in sociology, and also very important in research on law and society. While the concept of dispute is introduced, the process that accompanies a dispute is a more dynamic research pathway, in that it "transfers the focus from a dispute itself (and the techniques to handle a dispute) to a social process embedded in social relationships (Nader and Todd 1978, 2007)." From the perspective of process, the occurrence and development of disputes does not only happen at once but also involves a process of transformation and escalation. For instance, the classic theory of "the three stages of disputes" in the anthropology of law claims that a dispute follows stages including grievance, conflict, and dispute (third-party intervention) (Nader and Todd 2007). Some scholars point out that dispute formation refers to the naming of disputes in terms of facts and attributes, the blaming of others, and the claiming of rights from self-identified offenders (Felstiner et al. 1980-1981; Cheng and Wu 2010). During third-party intervention, some disputes require help by legal means (turning to the court). The aforementioned notion of the dispute process identifies different stages of transformation, ${ }^{1}$ but fails to focus on the state of disputes after turning to the court.

In contrast to the notion of "process model", the notion of "meaning model" deems that it is insufficient to study disputes with only a description; instead, their meaning system should also be examined. The process model provides only limited understanding of the

(C) 2016 The Author(s). Open Access This article is distributed under the terms of the Creative Commons Attribution 4.0 International License (http://creativecommons.org/licenses/by/4.0/), which permits unrestricted use, distribution, and reproduction in any medium, provided you give appropriate credit to the original author(s) and the source, provide a link to the Creative Commons license, and indicate if changes were made. 
complicated process of interpretation that occurs during interactions between two parties in dispute. "[The notion of a process model] assumes that disputes between parties unidirectionally proceed without accommodating their re-interpretation over disputes during the process... Disputes themselves do not transform. Instead, different subjects interpret meanings of events under different backgrounds with different dispute resolution approaches" (Merry 2007). Specifically, when subjects bring a dispute to court, the same dispute can be interpreted either as an issue or as a case. The boundary between the two rests on the interpretation of the meaning of a dispute, while whether to interpret it as an issue or as a case is determined by the attributes and state of the dispute (Merry 2007; Zhu 2010). Although "process model" and "meaning model" take different perspectives on the transformation of a dispute, they share the same inner logic, acknowledging the different states of a dispute (a dispute in the court is usually regarded as a case). However, they both ignore a central question: why is it that a dispute brought to court automatically is seen as a case?

In fact, transformation of disputes is not a simple process. The theory of filtering deems that during each stage of formation and transformation of disputes, the existence of various social mechanisms helps filter through a large number of cases until the dispute ends (Galanter 1983). In other words, not all disputes that are brought to the court through legal means will become formal cases. Through case filings, many disputes are disqualified and only a few will successfully be identified as cases (Ran 2005). Meanwhile, the original characteristics of disputes are diluted or filtered down following multiple legal procedures. Some studies describe this procedure as a "drying mechanism": legal procedures function as a fast rotating dryer that dehydrates extra "water" (items irrelevant to legal procedures, e.g., morals, habits, or experience) and dress up a dispute with a legal coat (Guo 2013; Liu 2014).

Is the drying mechanism sufficient to explain dispute transformation during case filing? In the legal practice of local courts, what is the common mode and procedure through which a dispute is transformed into a case? How do ordinary people interact with legal procedures during case filing? Through unscrupulous analysis on the casefiling procedure and its practical logic in a local court, this paper tentatively addresses these questions. This work also explains the interwoven relationship and interaction between systematic legal logic and the logic of daily life, and extends current research on the complexity of dispute transformation.

\section{Literature review and research method}

\section{Case filing as the core of dispute transformation}

Regarding dispute transformation, the "process model" identifies three stages: grievance, conflict, and dispute. The "meaning model", in contrast, categorizes disputes into issues and cases. More precisely, the two models imply the same assumption: no matter what state a dispute is in, it always has a corresponding solution. ${ }^{2}$ For instance, under the scope of the "process model", the ways of resolving disputes include tolerance, avoidance, and condemnation during the grievance stage. This model also comprises negotiation and suppression during the conflict stage and consists of mediation, arbitration, and adjudication during the third-party intervention stage (Nader and Todd 2007). From the perspective of the "meaning model", however, community and 
social groups can resolve disputes that are regarded as issues. Only disputes that are cases appear in the courts (Merry 2007).

In fact, existing studies on dispute transformation are usually closely connected to, or posited under, the scope of dispute resolution (Sandefur 2008; Cheng and Wu 2010; Xiao et al. 2014). A classic example is seen in the three fundamental assumptions of the dispute pyramid: first, at different levels, ${ }^{3}$ there simultaneously exist multiple ways to solve a dispute; second, most disputes can be resolved at relatively low levels, while only a few require input from legal procedures (the top of pyramid); third, the structure of a dispute pyramid is determined by the status of dispute resolution at each level. In the dispute pyramid, the more cases the legal procedures involve, the wider the top of the pyramid, which indicates that people rarely solve disputes at the relatively lower levels (Felstiner et al. 1980-1981; Chu 2010). Specifically regarding empirical research on Chinese society, Michelson (2007) amends the model of the dispute pyramid and advances the notion of a dispute pagoda. In his model, each stair of the pagoda is relatively disconnected. An increase or decrease in the proportion of resolved disputes at each level does not necessarily lead to changes at other levels, especially at the top of a pagoda. The models of pyramid and pagoda (hereafter referred to as metaphors of "two towers") share the same logic. Dispute transformation and resolution in these models display two interdependent but closely interconnected dimensions. Dispute transformation (from grievance to legal cases) is also closely related to the choice of approach in dispute resolution (from tolerance to legal appeals). The escalation of dispute transformation also means the approach to resolving a dispute must be more institutionalized and upgraded (Cheng and Wu 2010). Dispute transformation and the dispute resolution involve different contents.

The notion of two towers greatly pushes forward the understanding of the mechanism of dispute resolution. They accommodate dispute, the mechanism of dispute resolution, and the process of dispute resolution into one single model. This fact to some extent causes the hyper-stability of these models, which believes that all disputes locating at different levels would be resolved. However, a proportion of disputes in real life are not resolved, and existing models do not account for these unresolved disputes (Chu 2010; Guo 2013). These disputes may recurrently oscillate between different levels of near-resolution without ever being resolved and may even evolve to violence (Guo and $\mathrm{Qu}$ 2011). Dispute oscillation effect further reminds us that the dispute resolution may not ensure dispute transformation, though oscillation will positively correlate with dispute resolution. Clearly, dispute and dispute resolution are not in a one-to-one correspondence relationship. Not every dispute will reach a resolution.

Existing studies presume that a relationship exists between dispute and dispute resolution. Many studies follow the dispute resolution framework by default, while ignoring dispute transformation. This fact also implies the societally accepted position of the framework (Guo 2013). In fact, studies on dispute resolution do not focus on disputes themselves, but focus more on the interaction and the relationship between various social rules (including laws) (Chu 2010; Guo 2013). Studies on dispute resolution include mechanisms, as well as subjects and institutes for resolution, which are about answers to disputes (Xiao et al. 2014); studies on dispute transformation, in contrast, focus on the changing stages of a dispute (e.g., generation, development, and disappearance of disputes).

During the process of dispute transformation, legal systems will not view all preliminary-level disputes as appealing, and therefore not many will be escalated to 
become filed cases. The notion of "two towers" and related studies find that only a few disputes in real life can successfully enter the lawsuit stage. Yet, not all disputes brought to court are established as cases. The process of case filing is crucial in the transformation from disputes to cases. If this process were skipped, dispute transformation would contain a blank zone or break down. On the other hand, from the perspective of dispute resolution, transformation and escalation also mean that the dispute resolution process is more institutionalized. The role of lawsuits in dispute resolution is also controversial (Zhang 2009a). Case filing is the first step towards dispute resolution through a lawsuit. From this point of view, studying the case-filing process is important from two perspectives: it is not only a key procedure in the transformation from a dispute to a case but also a commonly followed procedure for the resolution of disputes through legal means.

\section{The research pathway for case filing}

For a long time, studies regarding case filing have generally two pathways. First is the normative research pathway followed in mainstream law schools, which focuses on the function and structure of case-filing procedures, the escalation of standards for case filing, and legitimacy constraints introduced by changes in legal policy (Zhang 2009b). This pathway claims that the Chinese procedure for case filing is bizarre but is so much a part of the Chinese system that it would be difficult to change. The fact that the case-filing procedure used in China is so unlike those used elsewhere in the world makes it difficult to extract value from comparative studies (Fu 2011). This comparative line of research has focused more on the applicability of standard procedures followed in China and advice about legislation (Duan 2012) but attends to the practical logic of the case-filing procedure in only a limited way. Detailed empirical analyses are also limited. On the other hand, the empirical pathway represented by the sociology of law cares about the conditions and practical logic of dispute-to-case transformation, and analyzes the complexity of case filing from different perspectives: One is that, at the macro level, most disputes at the grassroots level are solved through social and political means; only a few enter the legal system (Michelson 2007, 2008; Liu and Wu 2010). However, the empirical pathway cannot prove that legal solutions to disputes are unimportant but only introduces the question of whether or not a case-filing mechanism is reasonable. Second, from an organizational perspective based on the court system, the case-filing mechanism is closely related to the court's operations. For instance, from a political perspective on case filing, it is clear that courts need to consider both the form of case filing and its relationship to local social stability and cohesion, as well as its relationship to Party and government departments. The problem of when a case should be filed can be considered either as a legal issue or as a political and social issue (Ying and Xu 2009). Thirdly, some individual characteristics (e.g., beliefs) may also influence which cases are filed, especially plaintiffs' legal beliefs, which may change as their interactions with the legal system become more protracted (Gallagher 2006). Some scholars claim that individuals who have worked to resolved disputes through the legal system in China may lack confidence about the justness of the legal system (Michelson and Read 2011). Others believe that individuals are generally satisfied with the experience of resolving disputes through the legal system (Landry 2008). It is worth noting that whether a case can be filed is influenced not only by the aforementioned external factors but also by changes to and the construction of 
discourse involved in the case-filing process. This may be because disputes are disposed of differently, depending on whether they are interpreted as an issue or a case (Merry 2007). Individuals' and judges' discourses demonstrate the connection between micro language practices and macro social processes (He and Ng 2013). Meanwhile, individuals learn legal jargon, prepare legal documents and the evidence required by the courts, and tolerate long waiting times for case-filing decisions, all of which happens during dispute transitions (Su 2000; He et al. 2013).

The above studies show that filing a case can become the key to dispute transformation, after a dispute is put forward to the court. Whether or not filing a case can achieve success is full of uncertainty. Case filing occurs when ordinary people from the living world ${ }^{4}$ enter the legal system and requires a micro interactive process between ordinary people and legal experts (Liu 2007). Within the boundaries of case filing, there exists the world of state laws, while outside a case is under the domain of social systems or the administrative power of the state (Chu 2012). Studies on the case-filing process can deepen our understanding of the complexity of dispute transformation and provide new research perspectives.

This study is based on my field investigation of the people's court in County A, which began in 2006. During this investigation, I collected a considerable number of case documents and other materials and obtained audio materials by reviewing court debates and interviewing judges. The study materials can be categorized to three types. The first type includes various types of court documentation, including legal statistics, case assembly materials, conference notes, written rules and principles, and case documents. These documents serve as the basis for the document analysis. The second type includes operational documents from the court, which have been coded and categorized by reviewing court debates and through direct observations. The third type includes materials regarding the judges and subjects involved in disputes, including indepth interviews with judges from different departments. These different departments include the case-filing court, civil courts, department of archives, department of research, executive court, and sub-courts in villages and towns. Moreover, through daily interactions, this study also includes some supplemental interview materials obtained in canteens, restaurants, and dorms.

This study begins with the case-filing procedure and primarily focuses on the mechanism and practical logic of transformation from disputes to cases. The remainder of this paper is arranged as follows: the third part explores the change in nature from disputes to cases, displays the processes of definition and legal naming of disputes, and describes the mechanism of internal filtering. The fourth part studies the external transformation from disputes to cases, explaining the process by which disputes are formalized and documented, and the mechanism of external packaging. The last part discusses the case-filing procedure, summarizes the definition and meaning of dispute formatting, and interprets the mechanism of filtering/packaging, before connecting this work to other related studies.

\section{"Internal filtering": the change in nature from disputes to cases Definition of disputes-defining adjudicability}

In local courts, people coming to the court for the first time usually feel uncomfortable with the case-filing process. ${ }^{6}$ Some of them are totally unaware of the importance of filing a case. Although these individuals always have had the idea that they can appeal to 
a court to resolve disputes, they usually behave without much understanding during the case-filing process. Many plaintiffs do not hire lawyers at the beginning and may even lack the sense that they will need a lawyer. Consequently, during the case-filing process, plaintiffs naturally seek advice from judges.

Judge A: People usually directly turn to the court. They ask us about how to deal with the dispute. Some people come directly and ask "Am I able to win this case in the court? Can I get the money?" or "How likely are we to win this case?" If it is a divorce case, they will say a lot of details and ask if they can successfully divorce.

Interviewer asks ${ }^{7}$ : Do you have patience to let them finish talking?

Judge A: Of course not. I sometimes stop them. Sometimes, I listen to them for a little bit. If it is not too much, I will listen. Then we will tell then, we don't have answers to those questions. Those questions are for judges during the court debate. Also, that's the plaintiffs' own narrative. We cannot give them random answers like "Oh, you can win it". They will later say, "Oh, a judge just said that". People are like that. Sometimes, I will say, "You need to consult with lawyers for this type of question...go and get a lawyer and ask no more questions."

Judge A's words show that due to limited legal knowledge and traditional views, people usually adopt the form of self-appeal at lower level courts. Judges responsible for filing cases are usually the first person that a plaintiff consults. Judges assume both the responsibility for case filing and for legal consultation. At the same time, they also filter and exclude unacceptable cases. According to Term 119 in the "Civil Law" (2012), ${ }^{8}$ a lawsuit must meet the following conditions: (1) Plaintiffs are citizens, legal representatives, and organizations whose interests are immediately involved; (2) the defendant is known; (3) plaintiffs have detailed appealing and related facts and reasons; (4) cases must be under the domain of civil lawsuits and the geographical domain of the administration of the people's courts. The review of all the above conditions of lawsuit is usually not disclosed and is related to changes in legal policy in different times and regions (Zhang 2009b). Only a dispute that meets the above conditions can be admitted as a case. However, many plaintiffs in County A request a winning outcome but rarely consider whether their disputes are qualified to be filed as a case. According to Gallagher (2006), although plaintiffs only have obscure and incorrect knowledge about their ascribed rights and about legal procedures, they have high expectations that they can obtain protection from courts. As they engage with the legal system, plaintiffs' legal sensibility changes along two disconnected dimensions: feelings of legal power and its effects, and evaluation and beliefs about the legal system. When judges in the case-filing system explain whether or not a case can be established according to legal terms and adjusted according to legal policy, they are actually conveying a message about the effect of the law and the idea of the legal system.

Chinese courts have long adopted "case filing with screening", 9 rather than with registration. ${ }^{10}$ When screening disputes, courts (specifically, the judge responsible for filing a case) only have the opportunity to admit a portion of disputes through the operation of laws, in order to streamline the adjudication process. Some disputes are 
filtered in the process of case filing. Only filtered disputes can formally enter the legal process (Guo 2013). The above screening and filtering processes include a legal evaluation of the condition of a dispute, such as whether or not the dispute is under the scope of the case filing. If a case does not fall within the court's responsibility, then it is not admitted. The legal evaluation of conditions of acceptance is always transparent, while lower level courts keep the political conditions of admission hidden (political evaluation), as a result of the sensitivity of specific disputes as well as local policy. For instance, it is clearly acknowledged that the following types of disputes in the people's court of County A must receive approvals by vice presidents before these cases can be filed: (1) disputes related to social and political stability, especially sensitive cases, and class suit (2) cases that must be heard for special reports by the Party Committees, the People's Congresses, and the upper-level courts, (3) cases related to governmental matters above the level of country and street, or at the city level, and (4) other cases that need reporting. ${ }^{11}$ The court office responsible for case filing cannot decide to admit these types of disputes, because they are related to political and social stability. Instead, such cases have to be checked by court leaders who have more sensitive political consciousness. Initially, courts would avoid controversial issues. A dispute that can be tried does not only depend on meeting legal conditions but also depends on meeting local requirements regarding social and political stability. This is referred to as "politically legal logic" (Ding 2014). In the process of a lower level legal practice, the legal process (including case filing) is a complicated organizational and political process where multiple subjects (e.g., presidents and vice presidents of courts, judges, local officials) all can exert influences. Legal procedures are usually influenced by local governments, while local political legitimacy to a large extent formalizes the operations of the legal process (Liu 2005). This fact also reflects the competition between the inner logics of the specific power relationship and legal operations in legal practice (Bourdieu 1999). Specifically, during a case-filing procedure, the competition is reflected by filtering out various disputes that are difficult for a trial resolution or related to the benefit of court-level governments. In other words, power constrains dispute qualification such as whether or not a case can be filed, whereas laws constrain the domain, such as the types of disputes and cases.

\section{Legal naming of a dispute-the reason for a case}

Fortunate cases that are able to pass checks by case-filing judges and the vice president of courts are still not cases. To be a case, a dispute needs to obtain a name in a legal sense, which is the reason for the case. The reason for the case reflects the attributes of its civil legal relationship. After a case-filing court accepts a plaintiff's request to proceed with the case as a lawsuit, the case still must go through some legal operations, in order to name it with a corresponding name-the reason for the case-from the system of legal rules and principles. Various names exist to describe the reason for a case. In civil case reasons, for example, it is common to see divorce, contracts for purchase and sale, financial transactions, labor disputes, and property ownership.

Naming a case is firstly about the type of case. The reason for a case is confirmed by how facts and the sources of facts are conceptualized, indicating that disputes are categorized into different types of legal statistics. Merry (2007) claims that individuals who have the advantage of explaining the reasons for a case can determine the approach to handing 
disputes. Her research on lower level courts in the USA finds that tension usually arises between plaintiffs and courts as they state the reason for a case. Courts usually name disputes as moral or treatment problems and adopt non-legal approaches, whereas plaintiffs attempt to name disputes as legal cases and request that courts handle them in a legal manner. The reason for a case corresponds to a legal relationship. The choice of a reason for a case affects its legal basis, and even case attributes, such as whether mediation or trial is applicable. Although it is said that China respects the plaintiffs' rights to determine the reason for a case during the legal process, in practice plaintiffs are usually unfamiliar with how the meaning of a reason for a case can affect the later legal operations. It is common to see delegate judges file reasons for cases on the behalf of plaintiffs in lower level courts.

Judge B: We should not determine the reason for a case; it should be determined by the plaintiff according to the rule. For a case, they can reason from one angle or from another angle. We need to respect plaintiffs. However, sometimes a reason can be straightforward, such as a loan dispute, but they did not write anything. We then file it for them. There is no need for a discussion on it, right? But, you need to consider some other cases, when different angles have different perspectives. For example, when a passenger is injured in a coach, is it better to do it as a traffic accident or from the angle of a passenger contract with a bus company? The choice should be made by plaintiffs, rather than us.

Ask: What is it in fact? Do judges complete all reasons for cases?

Judge B: Of course not. We ask them from which angle they would do their cases. Lawyers know, but plaintiffs usually are unclear about them. You need to ask them, but they usually say they know nothing. Then I need to explain it to them. From one angle, it would be like this. From another angle, it would be like that. But the case reasons can be very different.

In this sense, the same disputes, incidents, people, and behaviors can be explained by totally different names and interpretations (Zhu 2010). A case name usually originates from a legal field, but not from the field of social relationship. Different names indicate different ways to achieve settlements. Previous legal experience and guidance from a plaintiff both have strong influence towards determining the reason for a case (Merry 2007). Laws usually ask plaintiffs to integrate their lawsuit appeal into appropriate case reasoning, when they appeal to courts. Ideally, when plaintiffs have a good sense of the law, they can discuss reasons for the case with judges. But in practice, judges usually dominate the interpretation of reasons for cases in local courts, because plaintiffs usually lack knowledge of the law. The legal process proceeds after step-by-step explanations and guidance from judges. In other words, judges obtain the right to explaining case reasoning because of their professional knowledge, while plaintiffs cannot claim their rights to determine case reasoning because of their poor legal knowledge. It is clear that the determination of the reason for a case does not merely rely on legal rules but also depends on the practical interactions between judges and plaintiffs.

Also, the establishment of reasons for a case is related to flexibility in case filing, ${ }^{12}$ and helps judges grasp the focus of disputes. "Rule of case reasons" (2011) specifies that choosing an appropriate case reason is the obligation and responsibility of plaintiffs. Courts 
also need to respect plaintiffs' choices rather than choosing for them. If a plaintiff files a case reason that is incorrect, but does not change it after the judge's explanation, the appeal should be denied. In practice, courts usually correct inappropriate case reasons through explanations, in order to avoid confusion over legal relationships in later trials. This establishment of case reasons is closely related to the use of language, because "law is the law of language...morals and ethics may be included in human actions, but laws are generated by languages (Tiesma 2000; Guo 2013)." According to the rules of upper-level courts, the people's court in County A does not admit cases related to "grain allowance". However, under the case reason for "land arrangement" disputes, ${ }^{13}$ cases related to grain allowance can still be established. Here, case reasons for disputes in a legal sense can be fabricated with language. Language as a tool that laws borrow to achieve most targets can also be an important scheme by which legal power can be realized and can operate (Conley and O'Barr 2007).

Thirdly, although establishing a case reason is only a small step during case filing, its influence can be lasting in the later trial. Since a case reason can affect corresponding strategies in a trial and the applicability of laws, case reason is always importantly described as "pulling one hair may move the whole body" (Ding 2014).

Judge D: Case reasons have an effect on trials. At the beginning, case reasons by the office for case-filing may be incorrect. After the trial, case reasons fix the standard of the lawsuit. One case reason is related to one lawsuit target...the office for case-filing constructs a case reason aimed at establishing a certain legal relationship...In practice, the case-filing office may file a case reason as an agency relationship, but in the trial we may find it is a loan relationship. That is to say, different relationships have different applicable laws. You have to change the case reason, right? Then judges have to exercise their right of interpretation.

According to the civil procedure, naming the wrong reason for a case may affect its qualification, trial, and applicable legal terms. Strictly speaking, a case with a wrong case reason requires a big change in the trial procedure, in order to correct mistakes in its case filing. However, in actual practice, it is not so. Judge E frankly said: "Case reasons can be adjusted during the trial process, which emphasizes substantive justice rather than the procedural justice advocated by laws."

Changing case reasons is only one of the methods that courts use to attempt to manage, run, and handle disputes. During every step of the legal process, there are debates over whether a dispute should be explained as an issue or a case (Merry 2007). The strategies implemented by courts (e.g., whether or not to file a case, to mediate, or to take a case to trial) are determined by the case reason assigned to the dispute. The case reason also reflects a legal relationship, category, and corresponding legal strategies for the dispute. Thus, naming a dispute is not simply a matter of assigning a legal label to a case. Rather, it reflects that the dispute has been transformed, so that abstract legal rules are now connected to the complicated real-life world.

Finally, when a dispute has a case reason and moves beyond the screening process, it is internal filtering through the case-filing process. Through interactions between plaintiffs and judges responsible for filing cases, a dispute as a case acquires a new meaning (Merry 2007). As a simile, we can think about disputes as a kind of unprocessed, early stage wine; later, the wine will be mixed and its concentration is reduced. We can think of 
this process as the "internal filtering" stage. In the same way that this internal filtering prepares a wine for sale, so disputes are processed through internal filtering to become a case. Not only are non-legal factors such as morals and habits are extracted from the process (Liu 2014), but disputes themselves are also transformed. In other words, internal filtering includes both extractions (filtering of non-legal residuals) in a physical sense, and adulteration in a physical-chemistry sense. In other words, during the transformation from original wine to finished wine, a vintner must filter residuals, control the temperature and time, and also dilute the alcohol with water and other additives to produce a high-quality wine. Vintners who can produce wine and faithfully complete the wine process need professional training and personal experience in order to handle the procedure both accurately and appropriately. Similarly, the defining and naming of disputes requires legal filtering and adulteration, whereby some disputes are removed from consideration by the courts, including disputes with political, policy, or social factors, the facts of the dispute are conceptualized according to legal relationships, disputes are constructed according to legal terms, and disputes are re-interpreted according to appropriate case reasons. Case-filing judges to some extent play the role of vintners. Through their definitions and the legal naming of disputes, they complete a dispute-case transformation, internal-filtering the dispute from its original state to a product state consumable by the courts. However, until this transformation is complete, disputes are still not enough to be cases. They still need external packaging.

\section{"External packaging": the form transformation from disputes to cases Formalization of disputes-litigation materials}

To meet the form demands of case filing, plaintiffs need to provide at least three types of litigation materials: lawsuit appeal, evidence, and identity information.

\section{Lawsuit appeal text}

"Civil Law" (2012) requires that plaintiffs submit the text of lawsuits to people's courts. Case-filing judges firstly care about how plaintiffs can convert their different lawsuit appeals into a uniform text format. A uniform lawsuit appeal usually contains the following elements: (1) plaintiffs (names, genders, age, ethnic groups, birthplaces, professions, and addresses); (2) defendants (names, genders, age, ethnic groups, birthplaces, professions, and addresses); (3) lawsuit appeals; (4) facts and reasons; (5) signatures. The following table provides an example of a lawsuit appeal text from 2012.

\footnotetext{
Lawsuit Appeal Text of People's Court in County A

Plaintiff: XXX, female, born on XXXX Year, XX Month, XX Day, Han Group, Farmer, Address: XXXXX.

Defendant: villagers' committee in Village $X X$, County $X X$,

Lawsuit request: 1. Defendant should compensate RMB 10000 as the land relocation fee for plaintiffs;

2. Defendant is responsible for fees involved in this lawsuit.

Facts and reasons:

In Jan 2012, the defendant paid RMB 10000 relocation fee for every villager according to the "Plan of Allocating Land arrangement Allowance" approved by the villagers' congress. However, the plaintiff was excluded because she had gotten married and was living with her husband in another village.

The plaintiff claims that as a villager (her hukou is in this village), she should receive treatment equal to that of other villagers, and she should receive the relocation fee according to the law. She then appealed to the court and asked for a trial.

Best Regards;

People's Court of County $X X$

Appeal filer: XXX

Date: Year X, Month X, Day X
} 
The above lawsuit appeal is made according to the "Civil Law" (2012) and is written in standard legal language, rather than including discursive, detailed, or emotional words. A lawsuit appeal text needs a pithy format without a detailed description of the facts. It only requires time, location, and the reason for a dispute. This appeal before a trial is obscurely referred to as though it is a legal process, but it does not specify the item of law that the court references. Neither detailed facts nor legal items are the key in a lawsuit appeal. Rather, the key is whether or not the form is correct. For instance, Judge A said: "we care about the form requirements when we file a case; while the content is related to a trial procedure...the explanation for a case should not be complicated, because the judge will ask them to say it again during the trial...the paper-based appeal only asks for the most basic content: 'facts and basics'."

The filed lawsuit appeal text displays the text structure of a case and reflects what a lawsuit is appealing. However, this structure may be to some extent different from the experience of plaintiffs and the facts of disputes. Disputes are usually accumulative, which cannot be reflected in a case text structure (Merry 2007). Since most plaintiffs cannot fulfill the requirement form of appeals initially, they usually ask lawyers for assistance or write the appeal under the instruction of case-filing judges. These are the two most common pathways. In local courts, some people even ask judges to write the appeals for them rather than only receiving instructions.

Judge C: Instructing a plaintiff on how to write an appeal is different from writing it for a plaintiff.

Ask: Have you ever written it for a plaintiff?

Judge C: What can I say? I did write for some relatives... but usually not. Sometimes, people would say, why are you so unhelpful? Chinese people always say, I am only asking you to do this for help, but why can't you do this? In fact, deeply in my mind, I don't feel judges should do this. You are the plaintiff, right? What is defendant going to do?...that's my understanding.

Here, the legal logic of procedural justice contradicts the social ethics of rural areas: judges want to maintain a neutral position and carefully obey the law. However, they usually provide some "easy help" for people who are their relatives, such as persons from the same village or their friends. (It is not uncommon for many plaintiffs to have such relationships with judges in the local court.) This is a Chinese-specific ethics obligation: forced by moral and relational pressures, emotional elements inevitably taint the case-filing procedure.

\section{Evidence material}

According to the rules of case filing, a plaintiff needs to provide some evidence. ${ }^{14}$ However, county courts are faced with a significant problem in that many plaintiffs only have the simple thought of "getting an objective judgment" and "asking for help", rather than the sense of evidence required by the modern legal system. Plaintiffs usually do not have corresponding evidence. So, when a case-filing judge asks plaintiffs for evidence, they usually received unexpected answers. Judge $\mathrm{H}$ offered an example, describing a plaintiff 
who said: "Evidence? I don't have evidence. The case is like this...Evidence? You just go to my village and ask. What I said is proof."

It sounds bizarre that evidence should rely on other villagers. But it is a fact that in rural areas asking for evidence from ordinary people is unrealistic. The above answers show the difficulty of the work of case-filing judges. According to Item 63 of "Civil Law" (2012), evidence includes plaintiff narratives but must be verified before being regarded as fact. ${ }^{15}$ Judges cannot accept narratives as legal evidence. As mentioned by Su (2000), "evidence is only evidence in a local network of meanings." Case-filing judges usually can only ask plaintiffs to collect evidence before going through the case-filing procedure. ${ }^{16}$ Even when asked, ordinary people can only bring very simple evidence. In the case of land arrangement, for instance, many plaintiffs can only provide the license for land-use rights.

Here exists the contradiction between rules of evidence as defined by law and the daily actions of ordinary people. A request based on legal procedure faces the impossibility of missing evidence. Ordinary people have a limited understanding of the need to retain evidence, since evidence is only a passport in the legal world, but not necessary in real life. Facts in the legal world must be based on evidence. Only through the evidence chain can facts be re-assembled using abstract legal symbols, concepts, and statements. At the onset of case filing, laws require plaintiffs, who are laymen, to structure their living problems or disputes within professional legal structures that are abstracted from the empirical world (Habermas 2003).

\section{Identity information}

Other than the identity information of plaintiffs, a case-filing procedure also needs plaintiffs to provide identity information of defendants. ${ }^{17}$ In most cases, plaintiffs only need to provide defendants' basic information such as names and addresses. However, in other cases, plaintiffs have not the ability when they are asked for more detailed information about defendants. Judge F said, "When they cannot get hukou information regarding defendants, our court will contact the public safety department. This makes me feel that we are like a service agency. I am concerned that we are not neutral. This is also the question I have been thinking about. This is not right. Does it violate the objective spirit of the laws? But if you ask people to obtain defendants' hukou information, it is impossible."

From the perspective of the objective position, judges should be partial to neither plaintiffs nor defendants. This meets the basic spirit of equal treatment, as required by procedural justice. However, in real legal practice, judges are embedded in social relationships. It is difficult and unrealistic to maintain objectivity. People turn to courts for help, which is not only aimed at getting a result but also because they want help with the process. This help can be as big as a legal remedy and as small as obtaining hukou information. Both kinds of help are the responsibility of the courts. Judges, however, need some balancing skills: they need to both hold the bottom line of procedural justice and also supply a service to plaintiffs in order to exhibit a strong affinity, namely, judicial activism for people.

\section{Documentation of disputes-forms}

After obtaining the text, evidence, and identity information for a lawsuit appeal, casefiling judges then make the "Form of Case-filing Approval" and deliver the "Notification of Admission" and the "Subpoena" to plaintiffs, before they pay for lawsuit fees. ${ }^{18}$ This 
compact procedure aims to deliver everything to a plaintiff all at once and to avoiding having a plaintiff come to court too many times. The people's court of County A also supports this policy of simplifying the steps of the procedure, according to the spirit of serving the people.

"The Form of Case-filing Approval" is filed by a case-filing judge and clearly mentions a plaintiff, the basic contents of an appeal, comments regarding the examination process, and the comments regarding its approval by leaders in the case-filing office. From a procedural sense, the most important information on this form is the casefiling date and a case-filing number. The former is related to the length of time before the related trial must end, which has either a 3-month or 6-month limit starting from the case-filing date. ${ }^{19}$ The latter carries a specific number for a specific case. After being assigned a case-filing number, ${ }^{20}$ a case then obtains a formal number, which is similar to an identity number.

"Notification of Admission" reiterates the appeal request, informs plaintiffs of their rights and responsibilities, ${ }^{21}$ and explains related issues, such as lawsuit fees.

One kind of important information in a subpoena is the date of the trial. The casefiling office usually decides the trial order. Separating the case filing from the trial is a remarkable feature that aims to ensure that judges cannot monopolize trials and hear cases for which they may have a personal bias. A case-filing office also has a corresponding schedule of cases that marks the trial date of a case. However, it does not specify which judge will preside over which trial. As Judge G explains, "After a plaintiff pays the lawsuit fee, the schedule table that identifies case and trial date arrangement then will include it." It has a date and location so that both parties can conveniently know the trial date. Still, it does not include the name of the judge, which is to avoid interactions between the two parties and the judge, because that may affect the judge's objective position. Occasionally, we might change a time or location, and will call and notify them."

In summary, through formalized materials by plaintiffs and documentation by courts, disputes are further packaged as cases. Every dispute has a case file that includes digital-management information, such as a case file number, a case file date, and a trial date, as well as a lawsuit appeal text, an approval table, a notification, and a subpoena. The establishment of the above case files maintains the imprint of handling a dispute, which renders this dispute handling process to meet the requirements of the legal process. It makes the case appear to be standardized, formalized, and legalized. The establishment of case files is also a documentation process completed in preparation for possible procedural checks that may need to occur in the future. "The legal requirement of case procedures and evidence is finally reflected as the legal production of case files, because all the evidence must be found within a case-file (Zhao 1997)." This practice skill of making the forms of case files (Zheng 1997) is usually found following the trial, such as refining the contents of case files, adding more materials, re-ordering all lawsuit documents, and creating a booklet from them (Ding 2014). This study analyzes the production of case files from the perspective of case filing and emphasizes the importance of case forms and the production of documentation.

This work compares disputes after internal filtering to wine production. After the stage of external packaging, formalized materials are like bottles of refined wine, which are also labeled with dates of production (dates of case filing) and series numbers 
(case-filing numbers). Similar to the process of wine production-from original wine to final wine to bottled wine to packaged wine (please refer to the below Fig. 1), disputes (original wine) meet legal requirements once they become a case (packaged wine). The case then waits to be handled in another space (trial court).

\section{Conclusion and discussion}

Although the legal gate will allow any dispute to be considered as a possible case, gatekeepers prevent some disputes from becoming cases. Only after passing multiple stages of checks and approval can disputes receive a passport and meet the legal requirements of laws (Bonsignore 2007). By analyzing the case-filing procedure and its practical logic in a county court, this work tentatively uncovers the mode and process of dispute-case transformation and finds that disputes in the life world can be admitted by legal procedure only after a process of dispute formatting. This work also attempts to advance the concept of dispute formatting, which means that disputes brought to courts are filtered (adulterated) and packaged according to legal procedures, before finally meeting the format of legal cases. From the case-filing perspective, this whole procedure that summarizes how disputes are transformed to become legal cases can be called dispute formatting. It includes defining, naming, formalizing, and documenting disputes; it exhibits two stages, including internal filtering and external packaging, and forms the mechanism of "filtering and packaging".

\section{The meaning of dispute formatting}

In the stage of internal filtering, defining a dispute means evaluating whether or not a case can be tried. Legal rules and political and social stability both intervene in this stage and shape the conception of the scope of legal power and the legal system. Dispute formatting also reflects the competition between the special power relationship and the inner logic of legal operations in the practice of law. The case checking process excludes many cases using the logic of political law, by constraining the rights of plaintiffs to appeal. This is also the reason for "case-filing difficulty". In order to implement the basic strategy of governing the country by law, our country has, since May 1, 2015, pushed forward the new scheme of case registration, which forbids admission conditions other than legal rules. Many illegal policies regarding case filing have been revised or abolished. ${ }^{22}$ However, case registration does not reduce the difficulty of bringing a lawsuit. It only focuses on checking over disputes brought to courts and still emphasizes legal formatting. On the one hand, the new law still emphasizes the conditions of lawsuits in the dispute check process. Courts are required to explain to a plaintiff why a case cannot be tried. ${ }^{23}$ It also stresses that laws should not be ignored because of

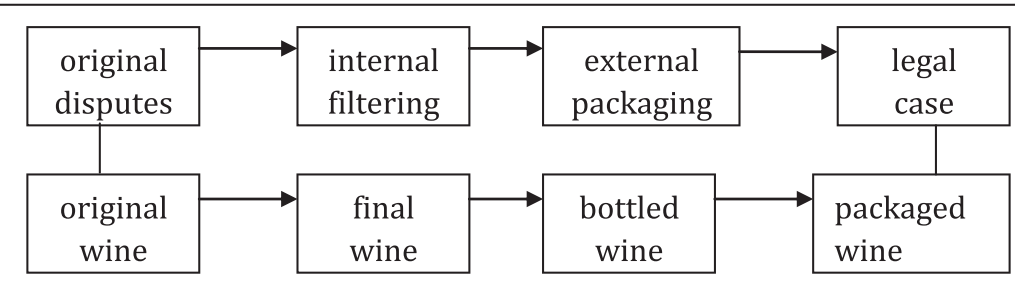

Fig. 1 Comparison between dispute transformation and wine production 
other factors and that courts should more closely follow the legal requirements to formalize and filter disputes. On the other hand, regarding the complexity of disputes, "Comments on Case Filing" (2015) and "Rules of Case Filing" (2015) both illustrate the types of cases that cannot be admitted, ${ }^{24}$ especially those not considered to be under the domain of the people's courts. This fact indicates that the new process of case registration does not necessarily mean all disputes can be accepted by the courts. This reform does not refuse case examination by the courts, but in fact asks courts to include the previous hidden procedure of dispute checking within the formal procedure, in order to give plaintiffs enough protection in the case-filing procedure (Xu and Yuanjie 2015).

The naming of a dispute (the case reason) displays the constructed and conceptualized facts and the source of facts obtained from explanations in daily legal practice. The interpretation right is inconsistent with the determination right of case reasons. With the help from the power of language, having a broader set of instances for when certain case reasoning apply can be an important approach to court and dispute management. In local courts, insufficient legal sense, legal knowledge, lawsuit ability, and experience leads to difficulty in identifying and choosing an appropriate case reason. Then case-filing judges' explanations of case reasons can exert a strong influence on plaintiffs. On the one hand, judges need to provide the necessary guidance and explanations to plaintiffs according to the spirit of "justice for people". On the other hand, legal practice requires that plaintiffs' right to bring a lawsuit be respected. In order to meet the format of case reasoning, adjusting case reasons is reflected as follows: plaintiffs advance disputes to courts and ask for legal solutions; but whether or not disputes are suitable for legal solutions or can be tried must be understood within the system of legal concepts and rules. Disputes are converted to cases after being defined and named. To describe this internal-filtering process, this work adopts the analogy of wine filtering and adulteration. After legal filtering and adulteration, disputes are modified to accommodate legal demands.

During the stage of "external packaging", disputes are formalized, as can be seen in the process of writing the text of the lawsuit, as well as in preparing evidence and identity materials. A lawsuit text that follows the appropriate formula displays a case structure and thus appears as a lawsuit appeal, and even references appropriate legal items. However, the structure of cases sometimes differs from the social facts about a dispute. The key point of writing a lawsuit appeal is to meet the legal requirements of case format. In order to construct daily problems within a professional and abstract legal structure, evidence, which serves as a passport to the legal world, plays an important role. The tension between evidence requested by laws and people's daily behavioral patterns grows across time. Moreover, the preparation of identity material requires defendants' information, in order to meet the requirement of case format. It is obvious that a plaintiff must have a lawsuit appeal with evidence and identity materials presented within an appropriate format for a dispute procedure, before the materials can be converted to a case. Disputes that do not meet the conditions of transformation and translation cannot be packaged as cases.

The documentation of disputes is a process through which courts use a series of forms to display disputes in the format appropriate for case files. Among these files, the "Form of Case-filing Approval" includes a case-filing date and a case-filing number, while "Notification of Admission of Cases" confirms plaintiffs' lawsuit appeals and 
informs them of their rights and responsibilities. A subpoena and a case arrangement form both mark the trial date of a case. Through the packaging that occurs with the arrangement form, each dispute has a corresponding case file that includes some digital information, such as a case-filing number, a case-filing date, a trial date, a lawsuit appeal, an approval form, a notification, and a subpoena. Then a dispute is maintained digitally with the support of multiple legal documents. With such elegant packaging of case files, cases also obtain a date of production and an inquiry number. The production of case files displays disputes in a documentation format that has been through as many processes as a well-packaged wine. This concludes the formatting process.

It is obvious that all steps of dispute formatting are designed to protect procedural justice. Although the operation is complicated, case-filing judges are willing to accept this procedural operation, which both alleviates any pressure they feel in handling disputes and decreases the number of responsibilities they must assume. As long as a case follows the required formula, case-filing results under the filtering-packaging mechanism can meet legal requirements. In the process of formatting, laws become a constraint on actions and limit the number of possible strategy options (Zheng 1997). In other words, some disputes have legal meanings and the values required in a trial, and can be solved by courts, whereas other disputes (such as emotional issues) are separate from legal relationships and cannot be connected to laws. The case-filing procedure controls the quality of a dispute: whether or not it meets the legal format. Only qualified disputes can be transformed so as to create a legal pathway for a solution.

\section{Extending the discussion over dispute formatting}

The extension of dispute formatting can be reviewed by comparing it to other related studies. This approach can also clarify the boundaries of this concept.

First, regarding the transformation of disputes, the aforementioned "process model" and "meaning model" represent two major pathways within existing studies. Among them, the process model acknowledges different stages of dispute transformation. However, it does not further focus on the state of a dispute once it is submitted to legal institutes. This work follows the idea of the process notion and attempts to fix the gap by analyzing the case-filing procedure. This work explains how disputes are transformed into legal cases from the perspective of case filing, emphasizing the mechanism of dispute transformation-filtering and packaging. I also include this transformation process as part of "dispute formatting". The meaning model advances the distinction between a problem explanation and a case explanation, and the competition between factors determining the property and state of a dispute (Merry 2007). Merry's study focuses on the fact that only if a dispute can be interpreted as a case can it be filed as a case and then enter into legal procedure. This work does not limit the scope only to the meaning of disputes, but attempts to further our understanding of case reason. After a dispute is filed as a case, the multiple explanations of a case reason require both legal knowledge and language power, which leads to an inconsistency between the interpretation right and the determination right of a case reason. Case-filing judges in local courts determine the interpretation right of case reason, by using their professional expertise and technical language. In contrast, a plaintiff's right to determine a case reason usually cannot be realized, because of their shortage of legal knowledge and related experience. 
Second, regarding the case-filing procedure, this work emphasizes the importance of case filing and primarily studies it. The aforementioned models of pyramids, pagodas, recurrent disputes, and the filtering effect should be distinguished during the case transformation procedure. It is worth noting that not all disputes can be converted to cases. The key to this transformation is the case-filing procedure. Otherwise, there is a blank and gap in the transformation of disputes. However, regarding the key issue of case-filing logic, normative studies of mainstream legal scholarship lack detailed empirical materials for analysis. Also, studies of legal sociology are scattered: they include organizational perspectives, ethics, and languages. This study on dispute formatting attempts to answer two key questions of case-filing logic: First, what is the mechanism of case filing? This work advances the filtering-packaging mechanism of dispute transformation. Most previous studies on case filing (Zhang 2009a; Fu 2011) focus on the difficulty of case filing (including case checking) but pay less attention to the inner mechanism of the case-filing procedure. Second, how does the case-filing mechanism operate? This work describes and analyzes the multiple interactions between subjects and judges through definition, naming, formalization, and documentation of disputes. Previous studies on legal sociology rarely examined the contour of the legal system through case filing. This work attempts to address this gap.

In general, neither theories of process and meaning nor existing studies fully answer the classic question of whether or not disputes brought to courts are cases. This work studies dispute formatting and attempts to address this question as well as to explain corresponding procedures and mechanisms.

Thirdly, the drying mechanism has explanatory power to explain the legal process. This work offers three extensions to the dispute formatting process: First, for research objects, the drying mechanism mainly has secret and informal effects, which occur throughout the lawsuit process until the trial is held (Liu 2014). Most studies on this mechanism focus on the whole lawsuit process and do not emphasize the key point of dispute transformation in case filing. Also, very few studies from legal sociology specifically focus on the case-filing procedure. This study specifies the effect of the drying mechanism on the case-filing process. Second, previous studies on the drying mechanism are mostly based on cases of divorce (Liu 2014) and deeply analyze the competing ethics between the two parties. They rarely focus on the case-filing procedures for general disputes, nor do they consider the working mechanism inside the courts, such as procedural operations, labor division, and the naming of case reasons. This study of dispute formatting amends these aspects. Third, drying and its auxiliary mechanism mainly describe a physical process, while the study on dispute formatting that analyzes the internal-filtering procedure includes a physical-chemistry process. This process is similar to the production line that begins with the original wine and transforms it into a saleable product: in a similar process, the legal meaning of the dispute changes. Meanwhile, the stage of formalizing and documenting the external packaging (into standard materials) further embodies disputes with rich legal meanings. The external packaging of disputes is enriched with more legal characteristics than had existed in the previous step. The transformation from dispute (original wine) to case (packaged wine) does not only include drying but also the follow steps of adulteration and packaging. The mechanism of internal filtering and external packaging can better explain dispute transformation. In summary, the drying mechanism has some limitations in explaining the process of case 
filing, while dispute formatting and the mechanism of filtering-packaging can help reflect, specify, amend, and push forward the explanatory power of the drying mechanism in dispute transformation.

\section{Conclusion and limitations}

The transformation of disputes into cases that can be tried also involves the connectivity between two different social fields (Xu and Ou 2015). In terms of form, case filing is an abstract stage in the lawsuit procedure. In fact, every dispute must go through this stage before being admitted into the national legal system. Admitted cases are in the legal world, while others are within the power domain of societal or governmental administration (Chu 2012). Case filing is a window into lawsuit subjects, but it is also the only way to enter the court system. Courts can only admit disputes that can be tried, in order to function efficiently and realize legal and social goals. This is the important context for governing society using laws.

Moreover, by examining the interactions between ordinary people and legal procedures, this work carefully analyzes the whole case-filing procedure and finds that contradictions exist between systematic legal logics and living logics, as well as between legal practice and daily actions. "The detachment between the system and living world" mentioned by Habermas (1984: 196) has new interpretations from the perspective of the case-filing procedure. For instance, although courts are regarded as places for justice that follow facts and rules, rules in courts are based on legal items that demand a strict corresponding relationship between evidence and legal items. The rules for ordinary people are more general: they have apparent local characteristics and are less strict in the corresponding relationship. Laws are based on legal rules, while rules of the ordinary people refer to only ethics of justice. They have different domains. Also, for the goal of resolving a dispute, although both laws and ethics pursue justice, the court's goal is to achieve justice by examining detailed events and objects, while the goal of ordinary people is to achieve a synthetic and continuous justice that is a combination and balance of ethics, rules and laws (Wang and Wang 2012). Also, in the legal language of case filing, courts use normative, neutral, and straightforward legal language, whereas ordinary people use living language that is irregular, strongly emotional, general, and filled with moral judgment. Research on these contents as a part of the lawsuit procedure should be extended and deepened in the future.

In summary, case filing is needed for disputes to move to lawsuits and transforming disputes into legal problems that can be ruled by laws (Bourdieu 1999). Meanwhile, the living world formed through interactions and the legal system exhibits the decoupling relationship in a Habermasian sense. The behavioral logic of the living world can hardly affect the operational logic of the legal system. In a highly differentiated and selfsufficient legal system, legal agents use different languages and logics from those adopted by ordinary people in daily life (Liu 2007). As Habermas (2003) has said, laws are not only normative, but also about facts. In the realm of law, the inner tension between legal facts and norms is reflected in the tension between definite rules and the application of laws. This tension guarantees the ruling power of the legal world on the living world and helps the legal world obtain basic elements from the living world. This tension prevents the legal world from detaching from the living world and also 
represents legal rules in the living world, as these two parties maintain a mutually constraining relationship.

This work attempts to deepen our understanding of the complexity of dispute transformation, but also has some limitations. First, focusing on details of case filing may lead to insufficient understanding of the entire legal practice. Second, this study attempts to clarify the importance of studying case filing through both dispute transformation and dispute resolution. By using empirical studies on the case-filing procedure to respond to various theories of dispute transformation and dispute resolution, the focus of this study is a little scattered. Third, this study attempts to advance the concept of dispute formatting in order to uniformly discuss and evince the process of dispute transformation during case filing. Although this concept is defined and compared from the perspectives of inner meaning and outer extension, this concept requires further refinement.

\section{Endnotes}

${ }^{1}$ It is worth noting that those stages are not simply disconnected nor do they necessarily proceed in a certain order. For instance, grievances can directly escalate into disputes, while disputes can also degrade to a certain level (Nader and Todd 2007).

${ }^{2}$ Solving a dispute in a narrow sense means that a dispute is resolved. Note that this emphasizes the outcome. In a broader sense, however, solving a dispute includes handling and treating disputes, which can be thought of as dispute management (Merry 1979; Zhu 2011). In this paper, solving a dispute refers to this broader sense.

3"Level" in this theory does not imply a hierarchy but only refers to different positions in the model.

${ }^{4}$ Here, the notions of the living world is borrowed from the social theory of Habermas, which refer to daily interactions that happen in families and communities and are defined by traditional ethics and norms (Habermas 2003).

${ }^{5}$ If not specified, the research and interview materials are all from the field research at the people's court of County A. In order to concentrate on the research goal, all cases involved in this study are civil cases that are being seen before the court for the first time, rather than administrative and criminal cases.

${ }^{6}$ Case filing, as studied in this research is meant in a broader sense, including the lawsuit and admission of cases in ordinary civil courts for the first court appearance and preparation before adjudication ( $\mathrm{Fu} 2011$ ). This definition is consistent with the working domain of case-filing courts, and case-filing procedures in actual legal practice.

7"Interviewer asks" refers to the questions raised by interviewers during field work. All subsequent uses have the same meaning.

${ }^{8}$ The legislation and legal documents are abbreviated as follows for brevity: "The Civil Law of the People's Republic of China", which was amended in 2012, is abbreviated as "Civil Law" (2012). "Regarding the explanations of 'The civil law of the People's Republic of China"' by the People's Supreme Court is abbreviated as "Civil Explanation" (2015).

${ }^{9}$ Lawsuit usually be reviewed by legal conditions or other factors before filing. Some disputes are filtered.

10"Regarding the suggestion to comprehensively expand reform in people's courts by the People's Supreme Court-the fourth outline of five-year-reform of people's court (2014-2018)"-was realized on Feb. 26, 2015. It specifically advances the goal of "changing the case-filing process from screening to registration." For disputes that 
peoples' courts must admit by law, the process now includes admitting them, filing them, and protecting individual's rights to file a lawsuit. This important topic of case filing drew broad attention from the whole society. On April 1, 2015, the 11th conference of the Central Leading Group for Comprehensively Deepening Reforms viewed and passed "Regarding the opinion for pushing forward the registration reform for the case filing system in the people's court". The People's Supreme Court printed and shared this opinion on April 15. This opinion has been active since May 1.

${ }^{11}$ This vague saying is common in official documents in China.

${ }^{12}$ In legal practice, lower-level courts for different regions may not be able to file a case without having an appropriate case reason. Regarding this, "Rule of Case Reason" (2011) points out that the amended "Rules of Case Reasons of Civil Cases" should not be seen as equivalent to Item 119 of "Civil Law", which defines the conditions of admission. Courts cannot deny case-filing appeals or hamper plaintiffs' rights to lawsuits by claiming that there is no applicable reason in the "Rules of Case Reasons of Civil Cases".

${ }^{13}$ Land arrangement disputes generally refer to disputes about land relocation allowance, which is a national allowance for compensating people who depend on their land as the major material for production and income generation, but relinquish their land according to governmental requests.

${ }^{14}$ According to Item 65 and Item 64 of the "Civil Law" (2012), plaintiffs have responsibility to raise and provide timely evidence to the court, in order to support their claims. Item 121 rules that lawsuit appeals must identify both evidence and the source of the evidence. Also, providing evidence is necessary both in the case-filing stage and in later stages.

${ }^{15}$ Item 90 of the "Explanation of Civil Law" (2015) points out that plaintiff must provide evidence about the facts that they use in their lawsuit appeals.

${ }^{16}$ Judges must guide plaintiffs in producing evidence and conducting necessary investigations and visits, in order to uncover as many facts as they can. However, in spite of this, Item 96 of the "Explanation of Civil Law" (2015) claims that evidence collection by people's courts must be in accordance with plaintiffs' applications.

${ }^{17}$ Item 121 of the "Civil Law" rules that a lawsuit appeal must include defendants' names, gender, work and home addresses, and legal representatives, or names of organizations (if applicable). Meanwhile, Item 3 of "Explanation of Civil Laws" (2015) points out that the home address of a citizen is their hukou location.

${ }^{18}$ According to Item 123 of the "Civil Law" (2012), courts should file all qualified cases within seven days and inform plaintiffs the filing result. In local courts, it is common that the decision about whether to file a civil case for the first trial is usually made on the same day, providing that plaintiffs have provided all relevant materials. The screening is also made on the same day, unless a court must discuss it, in which case they can extend their decision by at most seven days. The superior people's court also emphasizes this rule in "Regarding the Explanations of 'The Civil Law of the People's Republic of China" by the People's Supreme Court, which is abbreviated as "Rules of Case Filing" (2015).

${ }^{19}$ According to Item 53 of "Managerial Rules of the Trial Procedure of the People's Court of County A": (1) Civil or business cases that can be tried according to simple procedure should be granted a trial within three months of the date the case was filed; 
(2) Civil or business cases that can be tried according to ordinary procedure should be granted trial within six months of the date the case was filed.

${ }^{20}$ From a legal management perspective, a dispute being sent on to a court but without a case number is not a case.

${ }^{21}$ Please refer to Item 126 of "The Civil Law" (2012).

${ }^{22}$ Please refer to "Comments Regarding Pushing Forward the Reform of Case Registration" (2015) by the Supreme People's Court, which is abbreviated as "Comments on Case Filing" (2015).

${ }^{23}$ Please refer to Item 2 of "Rules of Case Filing" (2015).

${ }^{24}$ Please refer to the session of "Case Registration Realm" in "Comments on Case Filing" (2015), and to Item 10 of "Rules of Case Filing" (2015).

\section{Acknowledgements}

This research is sponsored by the National Social Science Fund of China (13CSH008), and Collaborative Innovation Center of Beijing Society-Building \& Social Governance.

\section{Competing interests}

The author declares that he has no competing interests.

Received: 27 May 2016 Accepted: 5 August 2016

Published online: 17 August 2016

\section{References}

Bonsignore, J. John. 2007. Before the law, trans Zibin Deng. Beijing: Huaxia Press.

Bourdieu, E. Pierre. 1999. "The power of law_towards a sociology of legal field", trans. Shigong Jiang. Peking University Legal Review 2(2): 498-499.

Cheng, Jinhua, and Xiaogang Wu. 2010. Social class and the resolution of civil disputes—social differentiation and legal development in transformation. Sociological Studies 2: 154-156.

Chu, Huijuan. 2010. The weak party in violence-extension to the traditional studies on dispute resolution. Academic Research 2: 61-63.

Chu, Huijuan. 2012. Evaluate the risk of strong men of rural orders from the perspective of violent crime. Society 3: 183. Conley, M. John, and William M. O'Barr. 2007. Law, language and power, trans Chaoyang, Cheng. Beijing: Law Press. Ding, Wei. 2014. Qinyao's court: the logic in elementary legal practice. Beijing: Sanlian Bookstore.

Duan, Wenbo. 2012. The case-filing procedure for first trial of civil cases. Comments on Legal Research 5: 141-142.

Felstiner, William L.F., R.L. Abel, and Austin Sarat. 1980-1981. The emergence and transformation of disputes: naming, blaming, claiming. Law and Society Review 15: 631-654.

Fu, Yulin. 2011. The function and structure of case-filing procedure of civil lawsuits in China. Jurist 1: 99-101.

Galanter, Marc. 1983. Reading the landscape of disputes: what we know and don't know and think we know about our allegedly contentious and litigious society. UCLA Law Review 31: 103-105.

Gallagher, Mary E. 2006. Mobilizing the law in China: 'informed disenchantment' and the development of legal consciousness. Law and Society Review 40: 783-816.

Guo, Xinghua. 2013. Dispute solution in social transformation. Beijing: Chinese Renmin University Press.

Guo, Xinghua, and Qu Qihan. 2011. Funnelization of dispute pyramids. Journal of Guangxi Ethnic University (Philosophy and Social Sciences Section) 4: 69-70.

Habermas, Jurgen. 1984. The theory of communicative action: lifeworld and system. Boston: Beacon.

Habermas, Jurgen. 2003. In Faktizitat und geltung, ed. Tong Shijun. Beijing: Sanlian Bookstore.

He, Xin, and Kwai Hang Ng. 2013. Pragmatic discourse and gender inequality in China. Law and Society Review 47: 279-310.

He, Xin, Lungang Wang, and Su Yang. 2013. Above the roof, beneath the law: perceived justice among migrant wage claimants in China. Law and Society Review 47: 703-737.

Landry, Pierre. 2008. The institutional diffusion of courts in China. In Rule by law: the politics of courts in authoritarian regimes, ed. Tom Ginsburg and Tamir Moustafa. Cambridge and New York: Cambridge University Press.

Liu, Sida. 2005. Law transplant and conflicts in legitimacy. Sociological Studies 3: 38-39.

Liu, Sida. 2007. The change in the meaning of legal work in contemporary China (1979-2003). Chinese Social Sciences 2: $91-93$.

Liu, Sida, and Hongqi Wu. 2010. Dispute resolution at legal boundary and professional system. Sociological Studies 1: $131-135$

Liu, Zhengqiang. 2014. Drying mechanism: the operational logic of the legal system in Chinese rural area. Society 5: $147-148$.

Merry, Sally Engle. 1979. Going to court: strategies of dispute management in an American urban neighborhood. Law and Society Review 18: 131-132.

Merry, Sally Engle. 2007. Getting justice and getting even: legal consciousness among working-class Americans. trans. Xinghua Guo, Xiaopei Wang, and Ping Wang. Beijing: Peking University Press. 
Michelson, Ethan. 2007. Climbing the dispute pagoda: grievances and appeals to the official justice system in rural China. American Sociological Review 72(3): 459-485.

Michelson, Ethan. 2008. Dear Lawyer Bao: everyday problems, legal advice and state power in China. Social Problems 55: 43-71.

Michelson, Ethan, and Benjamin L. Read. 2011. Public attitudes toward official justice in Beijing and rural China. In Chinese justice: civil dispute resolution in contemporary China, ed. Margaret Y.K. Woo and Mary E. Gallagher. Cambridge and New York: Cambridge University Press.

Nader, Laura, and H.F. Todd. 1978. The dispute process: law in ten societies, 1-40. New York: Columbia University Press. Nader, Laura, and Harry F. Todd. 2007. Dispute resolution from an anthropological perspective: material, method and theory, trans Xin Xu. Hongfan Review 8: 12.

Standing Committee of National People's Congress. 2012. Chinese law for civil lawsuit. Beijing: People's Court Press.

Ran, Jingfu. 2005. Study on the change of civil lawsuit in contemporary China- a sociological perspective of comparative law. Beijing: Chinese Renmin University.

Sandefur, Rebecca L. 2008. Access to civil justice and race, class, and gender inequality. Annual Review of Sociology 34: $112-120$.

Su, Li. 2000. Send law to villages a study on the elementary legal institution in China. Beijing: Chinese Renmin University. Supreme People's Court. 2011. Notification regarding printing and spreading "rules of filing case reasons of civil cases". Beijing: People's Court Press.

Supreme People's Court. 2015a. Explanations regarding cases applicable to the civil law of China. Beijing: People's Court Press.

Supreme People's Court. 2015b. Comments regarding pushing forward registration reform of case filing in people's courts. Beijing: People's Court Press.

Supreme People's Court. 2015c. Rules regarding several issues in the registration of case filing in people's court. Beijing: People's Court Press.

Tiesma, M. Peter. 2000. Legal language. Chicago: University of Chicago Press.

Wang, Hansheng, and Di Wang. 2012. Just construction and just logic mediation of civil disputes in rural areas. Society 2: 196.

Xiao, Yang, Fan Xiaoguang, and Lei Ming. 2014. Dispute involvement and response of Chinese urban residents under power effect. Society 1: 107-108.

Xu, Shanghao, and Ou Yuanjie. 2015. Case filing for every appeal—a study on the construction of case-filing scheme and case registration system. Shandong Social Sciences 7: 70-71.

Ying, Xing, and Yin Xu. 2009. 'Politics of case filing' and back and forth of lawsuit rate of administrative cases. Political and Legal Review 6: 111.

Zhang, Taisu. 2009a. Why do Chinese people prefer frog-jump petition faced with administrative disputes? Sociological Studies 3: 158

Zhang, Weiping. 2009b. Difficulty in lawsuit: reflection of a Chinese problem. Legal Study 6: 65-66.

Zhao, Xiaoli. 1997. Relations/events, narratives of action strategies and laws. In Just, order and authority in rural society, ed. Mingming Wang and Sifu Wang. Beijing: Chinese University of Political Science and Law Press.

Zheng, Ge. 1997. Rules, orders and traditions. In Just, order and authority in rural society, ed. Mingming Wang and Sifu Wang. Beijing: Chinese University of Political Science and Law Press.

Zhu, Tao. 2010. Discourse competition in legal practice. Sociological Studies 6: 227-230.

Zhu, Tao. 2011. The transformation of cases in local courts (1982-2008). In Laws and social sciences, ed. Su Li. Beijing: Legal Press.

\section{Submit your manuscript to a SpringerOpen ${ }^{\circ}$ journal and benefit from:}

- Convenient online submission

- Rigorous peer review

- Immediate publication on acceptance

- Open access: articles freely available online

- High visibility within the field

- Retaining the copyright to your article 